\title{
Gender Differences in Emotional Reactivity to Daily Life Stress in Major Depressive Disorder: Thesis Paper.
}

\author{
Dr. Parul Sharma
}

\section{Introduction:}

The interpretation of gender differences in depression has become the focus of much recent discussion. At present, the nature and extent of gender differences in depression stands as a contentious, complex and largely unresolved matter. The purpose of the present study is the better understanding of gender differences which may facilitate development of strategies in psychotherapy to alter the ways of patient's coping, to deal more effectively with stressors and reduce distress in depression.

\section{Material And Methods:}

The present prospective, comparative study aimed to find gender differences in emotional reactivity to life stress in patients diagnosed to have major depressive disorder. Sixty patients, thirty males and thirty females were taken in the study, attending outpatient and inpatient in department of psychiatry, Dayanand Medical College and Hospital, Ludhiana from 2006-2007.

\section{Inclusion Criterion:}

1: Patients diagnosed as suffering from Major Depressive Disorder as per DSM-IV diagnostic criterion.

2: Age between $18-40$ years.

\section{Exclusion Criterion:}

1: Patient with associated or co morbid psychiatric disorder as per DSM-IV diagnostic criterion.

2: Patient suffering from depressive episode of Bipolar Mood Disorder

3: Any diagnosed medical illness.

The following rating scales were used:

\section{Tools}

1: Socio demographic Performa.

2: Hamilton Depression Rating Scale.

3: ICMR Stress Scale.

4: Multidimensional Coping Inventory.

5: Emotional Competence Scale.

Data analysis was done by using student $t$ test. Coefficient of correlation was worked out to study the relation between different variables. Multivariate regression analysis was used to study the effect of different variables on depression.

\section{Results:}

*The mean age of males was in the age group of $41-50$ years and in females $31-40$ years ( $\mathrm{p}=0.55 \mathrm{~ns}$ )

*Maximum number of males and females were married $(\mathrm{p}=0.5423, \mathrm{~ns})$

*Maximum number of males were businessmen maximum number of females were housewives $(\mathrm{p}=0.0037$, highly significant)

*Maximum number of both males and females had studied up to matric/ $10+2$ ( $\mathrm{p}=0.0468$, significant)

*Maximum number of males had income range between Rs 1600-3199 per month and among females Rs 01599 per month $(\mathrm{p}=0.0067$, highly significant $)$

*Maximum number of males lived in joint families while among females, distribution between joint and nuclear families were equal ( $\mathrm{p}=0.02483$, significant $)$.

*Maximum number of males and females were urban residents. $(\mathrm{p}=0.1479$, nonsignificant)

HAMD score in females were slightly more than in males, but the difference was not statistically significant ( $>0.10$, nonsignificant)

*In both males and females, maximum ICMR psychosocial stress score was in the age group 51-60 year. P value was non significant $>0.10$ for both males and females in different age groups and also when males and females for different ages were compared. 
*The stress score according to age related ICMR stressful life event scale was maximum in males in age group 41-50 years and females in age group31-40 years. The difference was not found to be statistically significant ( $\mathrm{r}$ value in males $=-0.308$, in females -0.048$)$ ( $\mathrm{p}$ value in males $>0.10 \mathrm{~ns}$, females $>0.10$ )

*Gender related ICMR psychosocial stress score was more in females but the difference was not statistically significant ( $\mathrm{t}$ value in males was 0.53 , $\mathrm{p}$ value in females was $0.3113 \mathrm{~ns}$ )

*According to gender related ICMR stressful life event score , mean score was more in females than males but difference was not statistically significant( $\mathrm{p}$ value $=0.1486 \mathrm{~ns}, \mathrm{t}$ value $>0.40$ ) .

*The stress score according to Marital Status Related ICMR Stressful Life Event Scale was higher in married compared to unmarried males and females and score was higher in married females compared to married males but the difference was not statistically significant.

*Mean score according to occupation related ICMR psychosocial stress was more in nonworking men than working men (mean 32.10 versus 26.19), $\mathrm{t}=1.29, \mathrm{p}=0.1331$, ns, but the difference was not statistically significant. In females, mean values were more in working women than nonworking women and the difference was significant statistically (mean 35.67 versus 27.30 , t value $1.78, \mathrm{p}=0.0927$, significant)

*The analysis according to occupation related ICMR stressful life events showed that in males, stress score was more in working males compared to nonworking males.(mean 6.73versus6.00).

*Among females, working females had a higher score compared to nonworking females (mean10.00 versus 7.11) $\mathrm{p}=0.1187$ nonsignificant.

* Mean psychosocial score according to education related ICMR Psychosocial stress, was higher at lower education leveling both makes and females but the difference was not statistically significant $(\mathrm{p}=0.2869 \mathrm{~ns}$, $0.2791 \mathrm{~ns}$ )

*The stress score according to education related ICMR stressful life events was higher at lower education level in males and females. The difference was not found to be statistically significant.

*Income related ICMR Psychosocial stress score was higher at lower income ranges in both males and females but difference was not statistically significant.

Income related ICMR Psychosocial stress score was found to decrease with increase in income in both males and females but the difference was not found to be statistically significant.

The mean stress score according to family type ICMR Psychosocial stress was higher in joint compared to nuclear families in both males and females and difference was highly significant for males and significant for females(males mean 30.05 versus 21.64, $\mathrm{t}$ value -2.80 , $\mathrm{p}$ value $=-0.0092$, females mean 31.40 versus $24.87, \mathrm{t}$ value $=-2.41, \mathrm{p}$ value 0.0407$)$.

Family type related ICMR Stressful life event score was higher in joint compared to nuclear families in both males and females and difference was not statistically significant.

Place of residence related ICMR Psychosocial stress was higher in males living in rural areas and females in urban areas and difference was highly significant statistically for males ( mean 31.85 versus 23.24 , $\mathrm{t}$ value = 2.99 , p value 0.0086 , significant).In females, the difference was not statistically significant ( mean 26.50 versus $28.73, \mathrm{t}$ value $=-0.67, \mathrm{p}$ value $=-0.2463$, nonsignificant $)$

Place of residence related ICMR stressful life event score was more in males in rural than urban males ( $p$ value $=0.1410$, nonsignificant $)$ In females, score in urban residents was more than rural residents $(\mathrm{p}=0.0090$, significant)

Problem focused coping was found to be more among males than females and difference was statistically highly significant.

Emotion focused coping was found to be more in females than in males and difference was also highly statistically significant.

All emotional competence variables were significantly higher in males compared to females except emotional competence $\mathrm{E}$ (encouragement of positive emotions).

The results of correlation matrix between ICMR Psychosocial stress score and coping and competence variables showed that among females emotional competence $\mathrm{C}$ (ability to function with emotions was significant.

The results of correlation matrix between ICMR Stressful life event and coping and competence variables showed significant $\mathrm{p}$ value $<0.01$ ) for emotional competence B (adequate expression and control of emotions among males and emotional competence D (ability to cope with problem emotion) among females.

Problem focused coping was more in men than women $(\mathrm{p}<0.01)$.

Emotion focused coping score was more in females than males $(\mathrm{p}<0.01)$ and the difference was highly significant statistically.

All emotional competence variables were significantly higher in males compared to females except emotional competence $\mathrm{E}$ (encouragement of positive emotions). 
Among the different ICMR Psychosocial stress domains, it was found in interpersonal stress domain emotional liability domains, the score was higher in females than males and the difference was highly significant statistically.

In interpersonal stress domain the mean value for males $=3.40+2.98$ and for females $=8.31+2.46, \mathrm{t}$ value 6.7, $\mathrm{p}<0.01$.In excessive liability domain, mean value for males was $3.40=2.98$, for females it was $5.92=$ 2.48 , t value was $3.07, \mathrm{p}<0.01$.

In economic constraint domain and adverse social situation domain, the score was higher in females and difference was also highly significant statistically. Mean value of economic constraint domain in female was $7.43=3.49$, and in females $2.69=5.22$, $\mathrm{t}$ value was -5.22 , $\mathrm{p}$ value $<0.01$.In social situation domain the mean value in males was $6.40=2.34$, in females $4.67=3.43$, t value was 2.28 , $\mathrm{p}$ value $<0.10$.

\section{Discussion}

In the present study, the stressful life event score was seen to increase with age in both males and females. Similar observation was made by Singh et al $1984^{1}$. The higher psychosocial stress score at higher age group could be due to changes in life at this stage like problems of children's marriage, their settlement, property matters and health problems. Marriage related stress and settlement of self are also significant stressors in age group 21- 30 years but the number of subjects in this age group was lesser.

Mean ICMR Stressful life event score was higher in females similar to results of study by Kendler $2001^{2}$. However, significantly higher stress in females were seen in studies by Farabaugh et al $2004^{3}$ and Bolger and Kessel $1989^{4}$.

In the present study, stress score was more among married than unmarried males though difference was not significant statistically and in females, score was more in married ones.

Marriage increased stress in males and females but in unmarried group, females experienced lesser stress than males.

Fuller $2004^{5}$ and Amin $1998^{6}$ found that married men enjoyed higher level of psychological well being than do married women.

Cleary and Mechanic $1983^{7}$ found that marital satisfaction is less important in its effect on depression among working women than among working men. Ahnlund $\mathrm{K}^{8}$ also found that married women were significantly more prone to depression than were married men.

Earlier studies (Fuller $2004^{5}$ and Amin 1998) ${ }^{6}$ reported an increase in stress in married women but a decrease in men after marriage which is contrary to finding of present study which indicates increase in stress in males also after marriage. This may be due to more number of males with lower educational attainment and lower income range, both of which are associated with higher stress score. Cleary and Mechanic $1983^{7}$, also observed that employed married women experience slightly less distress than housewives as in the present study.The present study is in accordance with study by Hussain and Chaudhary $2007^{9}$ who also found unemployed men had a higher man Self Reporting Questionnaire score than employed men. Lower socioeconomic status people were found to have higher stress score among males. Similar observations were made by Kessler $1979^{10}$ and McLeod and Kessler $1990^{11}$.

Our finding that stresses score is higher among both males and females living in joint than nuclear families in contrast to findings of Kulhara and Chopra ${ }^{12}$ who found living in joint families increases the available support with large number of family ties. This could be due to more interpersonal events between larger number of family members and financial problems with disputes over property matters. Stress score was found to be more in males living in rural areas and more in females living in urban areas. The finding is not in accordance with study of Kulhara and Chopra ${ }^{12}$. This may be due to the fact that males get less job opportunities in rural areas while in women working in urban areas, stress is more due to multiple role responsibilities.

Step down regression analysis with ICMR Psychosocial stress as dependent variable showed that in males: place of residence, emotion focused coping, emotional competence A( adequate depth of feeling) $\mathrm{C}$ ( ability to function with emotions) E ( encouragement of positive emotions) were found to be significantly correlated with ICMR stress score.

In females: marital status, occupation, education, family type, emotion focused coping, emotional competence A (adequate depth of feeling) C (ability to function with emotions) E (encouragement of positive emotions) were factors that significantly correlated with ICMR Psychosocial stress score.

The analysis of results of step down regression analysis with ICMR stressful event as dependent variable showed that in males: age, occupation, income, emotional competence A ( adequate depth of feeling) $\mathrm{B}$ ( adequate expression and control of emotions, $\mathrm{C}$ ( ability to function with emotions) $\mathrm{E}$ ( encouragement of positive emotions) were significantly correlated with ICMR stressful life event scores.

Multidimensional coping variable analysis showed that among males: problem focused coping was significantly higher in men than in women, showing that in males strategies like active coping, planning, 
suppression of competing activities, restraint coping, seeking of instrumental and social support was significantly more than in women.

On the other hand, emotion focused coping was found statistically more significantly in women than in men, showing that strategies like seeking emotional support, positive re- interpretation, acceptance, denial and turning to religion, were used more in women than in men.

These findings are in accordance with study of Stone and Neale (1990) ${ }^{13}$ and Carver et al (1999) ${ }^{14}$.

Analysis of emotional competence showed that adequate depth of feeling (emotional competence A) which is feeling of being confident is significantly more in men.

Emotional competence B; which is regarded as the natural dynamic stability of an individual to express and control emotions spontaneously as demanded by situations was more in men than in women.

Emotional competence $\mathrm{C}$; which is not being easily influenced about highly emotional situations was observed significantly more in men.

Emotional competence E; those that show constructive influence on dynamics of behavior was more in men though not significantly.

These findings are in accordance with study by Gohm and Clore $2000^{15}$ who found women reported experiencing emotion more intensely and with greater reactivity.

However, women scored slightly higher than men in expression of positive emotion which is contrary to the result of present study. This could be due to more conservative nature of our study compared to western countries.

These findings show that traits of emotional expression like intensity, attention, expression were associated with coping by focusing on and venting emotions and seeking social support were more in males than in females, hence they cope better than females experience lesser stress. Higher is the clarity of emotion, more is the engagement in planful coping and reinterpretation of events.

Shih et al $2006^{16}$ also reported that girls displayed heightened stress reactivity especially to interpersonal episodic stress compared to boys.

Hoeksema $1994^{17}$ found that women's response to depression was that they focused on negative emotions while men used distracting responses to cope with depression. more in females.

Different domains of ICMR Psychosocial stress analysis showed interpersonal stress was significantly

The stress because of financial strain, marriage related problems; health related problems were more in males than in females but the difference was not significant statistically.

In males, stress due to perceived or imagined threats (social position, respect, position in profession, economic position, fear of sexual abuse) was more among females than males and the difference was significant statistically. The data is in accordance with study by Kendler $2001^{2}$. However, contrary to our findings, no significant gender difference was observed for the financial constraint.

\section{Conclusion}

Both males and females with Major Depressive Disorder experienced almost same stress in life, though it is perceived differently in the different domains by them. Genders were found to significantly differ in their ability to cope the stresses, with males using more practical problem focused coping compared to less effective emotion focused coping by females. Men were found to have significantly more depth of feeling, ability to express and control emotions, ability to function with emotions, ability to cope with problem emotions compared to women.

\section{Bibliography}

[1]. Singh G, Kaur D, Kaur H. Presumptive Sressful Life Events Scale (PSLES) - a new stressful life event scale for use in India . Indian J Psychiat 1984; 26(2) : 107-14.

[2]. Kendler KS, Myers J, Prescott CA . Sex differences in the relationship between social support and risk for major depression: a longitudinal study of opposite sex twin pairs Am J Psychiatry 2005; 162:250-256.

[3]. Farabaugh AH, Mischoulon D, Fava M, Green C, Guyker W, Alpert J.The potential relationship between levels of perceived stress and subtypes of major depressive disorder (MDD).Acta Psychiatr Scand 2004 ; 110: 465-70.

[4]. Bolger N, Kessler RC, Schilling EA, Longis Ad. Effects of daily stress on negative mood. Journal of Personality and Social Psychology. 1989; 57(5); $808-18$.

[5]. Fuller TD, Edwards JN, Vorakitphokatorn S, Sermsri S. Gender differences in the psychological well being of married men and women: an Asia case. The Sociological Quarterly 2004; 45(2) : 355 - 78

[6]. Amin G, Shah S, Vankar GK.The prevalence and recognition of depression in primary care. Indian J Psychiatr 1998; 40(4): $364-9$.

[7]. Cleary PD and Mechanic D. Sex differences in psychological distress among married people. Journal of Health and Social Behaviour 1983; 24: 111-21.

[8]. Ahnlund K, Frodi A. Gender differences in the development of depression. Scand J Psychol 1996; 37 (30): 229-37.

[9]. Hussain N, Chaudhary IB, Afridi MA, Tomenson B, Creed F. Life stress and depression in a tribal area of Pakistan. Br J Psychiatry 2007; 190: 36-41.

[10]. Kessler RC. Stress, social status, and psychological distress. Journal of Health and Social Behaviour 1979; 20: $259-272$. 
[11]. Mcleod JD, Kessler RC. Socioeconomic status differences in vulnerability to undesirable life events. Journal of Health and Social Behaviour 1990; 31: 162-72

[12]. Kulhara P, Chopra R. Social support, social dysfunction and stressful life events in neurotic patients. Indian J Psychiatr 1996; 38(1): 23-9.

[13]. Stone AA, Neale JM. New measure of daily coping: development and preliminary results. Journal of Personality and Social Psychology 1984; 46 (4); 892-906

[14]. Carver CS, Weintraub JK, Scheier MF. Assessing coping strategies: a theoretically based approach.Journal of personality and Social Psychology 1989; 56(2); 267-83.

[15]. Gohm CL, Clore GL. Four latent traits of emotional experience and their involvement in well beinh, coping and attributional style. Cognition and Emotion 2002; 16(4): 495-518.

[16]. Shih JH, Eberhart NK, Hammen CL, Brennan PA.Differential exposure and reactivity to interpersonal stress predict sex differences in Adolescent depression. Journal of clinical child and Adolescent Psychology 2006; 35(1): 103 - 15.

[17]. Hoeksema SN. An interactive model for the emergence of gender difference in depression in adolescence. Journal of Research on Adolescence $1994 ; 4(4): 519-34$. 